\title{
Enhanced $\mathrm{Ca}^{2+}$ Entry and Tyrosine Phosphorylation Mediate Nanostructure-Induced Endothelial Proliferation
}

\author{
Michaela Schernthaner, ${ }^{1}$ Gerd Leitinger, ${ }^{2}$ Heimo Wolinski, ${ }^{3}$ \\ Sepp D. Kohlwein, ${ }^{3}$ Bettina Reisinger, ${ }^{4}$ Ruxandra-A. Barb, ${ }^{4}$ \\ Wolfgang F. Graier, ${ }^{5}$ Johannes Heitz, ${ }^{4}$ and Klaus Groschner ${ }^{1}$ \\ ${ }^{1}$ Institute of Biophysics, Medical University Graz, 8010 Graz, Austria \\ ${ }^{2}$ Department of Cell Biology, Histology and Embryology, Core Facility Ultrastructure Analysis, Center for Medical Research, \\ Medical University Graz, 8010 Graz, Austria \\ ${ }^{3}$ Institute of Molecular Biosciences, University of Graz, 8010 Graz, Austria \\ ${ }^{4}$ Institute of Applied Physics, Johannes Kepler University Linz, 4040 Linz, Austria \\ ${ }^{5}$ Institute of Molecular Biology and Biochemistry, Medical University Graz, 8010 Graz, Austria
}

Correspondence should be addressed to Johannes Heitz; johannes.heitz@jku.at and Klaus Groschner; klaus.groschner@medunigraz.at

Received 23 August 2013; Accepted 6 October 2013

Academic Editor: Krasimir Vasilev

Copyright (C) 2013 Michaela Schernthaner et al. This is an open access article distributed under the Creative Commons Attribution License, which permits unrestricted use, distribution, and reproduction in any medium, provided the original work is properly cited.

\begin{abstract}
Nanostructured substrates have been recognized to initiate transcriptional programs promoting cell proliferation. Specifically $\beta$ catenin has been identified as transcriptional regulator, activated by adhesion to nanostructures. We set out to identify processes responsible for nanostructure-induced endothelial $\beta$-catenin signaling. Transmission electron microscopy (TEM) of cell contacts to differently sized polyethylene terephthalate (PET) surface structures (ripples with 250 to $300 \mathrm{~nm}$ and walls with $1.5 \mu \mathrm{m}$ periodicity) revealed different patterns of cell-substrate interactions. Cell adhesion to ripples occurred exclusively on ripple peaks, while cells were attached to walls continuously. The Src kinase inhibitor PP2 was active only in cells grown on ripples, while the Abl inhibitors dasatinib and imatinib suppressed $\beta$-catenin translocation on both structures. Moreover, $\mathrm{Gd}^{3+}$ sensitive $\mathrm{Ca}^{2+}$ entry was observed in response to mechanical stimulation or $\mathrm{Ca}^{2+}$ store depletion exclusively in cells grown on ripples. Both PP2 and $\mathrm{Gd}^{3+}$ suppressed $\beta$-catenin nuclear translocation along with proliferation in cells grown on ripples but not on walls. Our results suggest that adhesion of endothelial cells to ripple structured PET induces highly specific, interface topology-dependent changes in cellular signalling, characterized by promotion of $\mathrm{Gd}^{3+}$-sensitive $\mathrm{Ca}^{2+}$ entry and Src/Abl activation. We propose that these signaling events are crucially involved in nanostructure-induced promotion of cell proliferation.
\end{abstract}

\section{Introduction}

Understanding the basic mechanisms by which cells recognize and respond to specific surface topologies is of outstanding importance for the development of novel biomaterials to advance tissue engineering applications. We and others have demonstrated that growth of vascular endothelial cells is governed not only by the type of culture substrate and its surface chemistry but also by surface topography [1-3]. Many studies have focused on optimisation of the biocompatibility of polymer substrates to improve cell adhesion and promote proliferation [4], while mechanisms underlying the control of cell functions by nanoarchitectured substrates remain elusive.

Micro- and nanostructures on polyethylene terephthalate (PET) substrates produced by laser irradiation were recently discovered to activate endothelial $\beta$-catenin signaling which leads to nuclear translocation of the transcriptionally active protein and enhanced proliferation of human microvascular endothelial cells (HMEC). The extent of these effects was dependent on size and periodicity of surface structure topography. In particular, transcription levels of the $\beta$-catenin target gene cyclin D1 were significantly different on ripples 
and walls. This observation led to the hypothesis that cell growth on various surface structures on PET substrates differentially activates specific pools of $\beta$-catenin [5].

$\beta$-catenin is an important signaling molecule in endothelial cells and part of adherens junctions. When released from contact sites or as newly synthesized protein, cytosolic $\beta$ catenin is phosphorylated by a destruction complex that includes glycogen synthase kinase $3 \beta(\mathrm{GSK} 3 \beta)$ which marks the protein for degradation by the proteasome [6]. Upon inhibition of this destruction, complex $\beta$-catenin accumulates and translocates to the nucleus where it binds to transcription factors and induces target gene transcription [7-10]. $\beta$ catenin possesses a multitude of regulatory phosphorylation sites, which are substrates of serine/threonine and tyrosine kinases [11]. Cell attachment to the extracellular matrix (ECM) can initiate clustering of integrins and activation of downstream targets such as integrin-linked kinase (ILK) [12], focal adhesion kinase (FAK) [13], or Src kinases [14, 15]. Src and FAK are able to phosphorylate $\beta$-catenin directly [16-18] or block its proteasomal degradation by inhibiting its phosphorylation by GSK3 $\beta$ via the phosphatidylinositol 3-kinase (PI3K)/Akt pathway [19]. Phosphorylation of FAK and $\beta$-catenin may also be controlled by stimulation of mechanosensitive ion channels [20] as well as by mechanical stress, which leads to enhanced calcium influx downstream of Src [21].

In this study, we set out to identify cellular mechanisms that trigger $\beta$-catenin translocation and consequently proliferation in endothelial cells growing on nanopatterned substrates. We demonstrate that adhesion of endothelial cells to nanostructured PET substrates activates $\beta$-catenin by enhanced tyrosine phosphorylation and calcium signaling through mechanosensitive ion channels.

\section{Material and Methods}

Laser generation and characterization of structured PET substrates, cell culture of HMEC, immunocytochemistry, and confocal microscopy were performed as described recently [5].

In short: for immunostainings, HMEC-1 cells [22, 23] were seeded on the different substrates and fixed and immunostained with the anti- $\beta$-catenin antibody $(1: 150$, BD Biosciences), anti-Ki67 antibody (1:300, Abcam), antiP397-FAK antibody (1:250, Abcam), or anti-VE-cadherin ( $1: 150$, BD Biosciences) after $48 \mathrm{~h}$ of culture. For the inhibitor experiments, inhibitors were added to the culture medium $6 \mathrm{~h}$ prior to fixation.

Nuclear to cytosolic ratios of $\beta$-catenin were determined by marking ROIs (regions of interest) in the phase contrast image for the nuclei and cytosols. The ROIs were then transferred to the corresponding fluorescence image and the mean fluorescence intensity for every ROI was determined, using Image $\mathrm{J}$ software. Finally, the ratio of nuclear to cytosolic intensity was calculated.

2.1. Reagents and Antibodies. All chemicals were purchased from Sigma Aldrich (Steinheim, Germany) unless otherwise stated: anti-Ki67 (1:300, Abcam, Cambridge, MA), antiTyr397-FAK (1:250, Abcam), PP2 (4-amino-5-(4-chlorophenyl)-7-(dimethylethyl) pyrazolo[3,4- $d]$ pyrimidine; Calbiochem/Merck, Darmstadt, Germany), imatinib (Cayman Chemical, Tallinn, Estonia), FuraRed AM (Molecular Probes, Life Technologies Corporation, UK), and BHQ (2,5di-t-butyl-1,4-benzohydrochinone).

2.2. Transmission Electron Microscopy (TEM). Cells cultivated on the different substrates were embedded with a small piece of their substrate. For this, they were fixed in a mixture of $2 \%$ formaldehyde, $2.5 \%$ glutardialdehyde in $0.1 \mathrm{M}$ sodium cacodylate buffer, $\mathrm{pH} 7.4$ for $1 \mathrm{~h}$ at room temperature. They were then rinsed in the same buffer, treated with $2 \%$ osmium tetraoxide (in the same buffer) for $1 \mathrm{~h}$, rinsed, and dehydrated in a series of graded alcohols. They were then embedded in TAAB epoxy resin (TAAB laboratories Equipment Ltd, Aldermaston, UK) with propylene oxide as an intermedium. Sections of $70 \mathrm{~nm}$ thickness were counterstained with uranyl acetate and lead citrate and visualised using an FEI Tecnai 20 (FEI, Hillsboro, OR, USA) transmission electron microscope operated at $120 \mathrm{kV}$ acceleration voltage. Electron micrographs were made with a Gatan Ultrascan 1000 CCD camera (Gatan, Inc, Pleasanton, CA, USA).

\subsection{Measurement of Intracellular Calcium Levels Using} FuraRed AM. Cells cultivated on the different substrates were loaded for $40 \mathrm{~min}$ at $37^{\circ} \mathrm{C}$ with FuraRed AM. Base levels of calcium content were recorded for $1 \mathrm{~min}$ before perfusion was started. Cells were continuously perfused with buffer containing $140 \mathrm{mM} \mathrm{NaCl}, 15 \mathrm{mM}$ HEPES, $10 \mathrm{mM}$ glucose, $2 \mathrm{mM} \mathrm{MgCl}_{2}$, and $2 \mathrm{mM} \mathrm{CaCl}_{2}$ and treated with $15 \mu \mathrm{M}$ 2,5-di-t-butyl-1,4-benzohydrochinone (BHQ) for $5 \mathrm{~min}$ as indicated. For preincubation, cells were treated with $10 \mu \mathrm{M}$ gadolinium chloride $\left(\mathrm{Gd}^{3+}\right)$ for $6 \mathrm{~h}$ before the experiment was started, and $\mathrm{Gd}^{3+}$ was present throughout the experiment. Measurements were carried out on a Till iMIC microscope (Till Photonics, Gräfling, Germany).

\section{Results}

3.1. Ripples and Wall Structures Generate a Divergent Pattern of Physical Contact with the Basal Membrane of Endothelial Cells. Experiments were performed with HMEC cultured on two different types of structured PET surfaces representing distinct range of pattern size. Ripples characterized by a periodicity of 250 to $300 \mathrm{~nm}$ were compared to walls with a periodicity of $1.5 \mu \mathrm{m}$ [5]. Electron micrographs of these structures are shown in Figure 1. Flat, pristine PET was used as a control to evaluate potential effects induced by the polymer itself. Lower panel of Figure 1 shows TEM images of HMEC grown on the different nanoarchitectures with focus on the contact area between cell membranes and the surface of the substrate.

Contact between the basal membrane of the endothelial cells and flat, pristine PET surfaces is continuous and straight, whereas punctual contact sites are exclusively observed between the basal endothelial membrane and the peaks on 

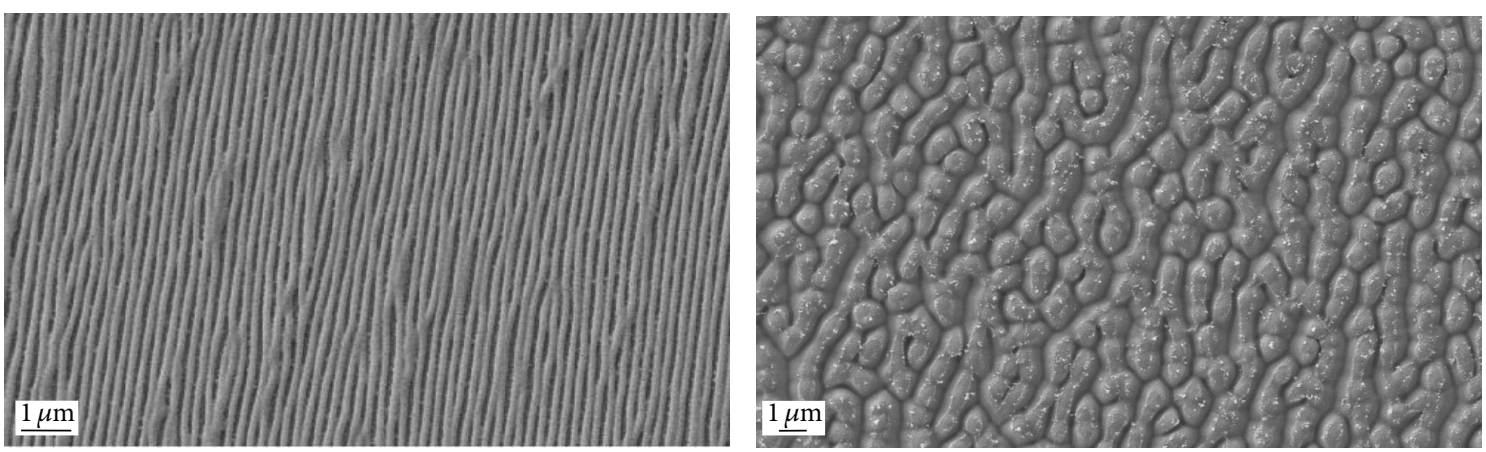

(a)
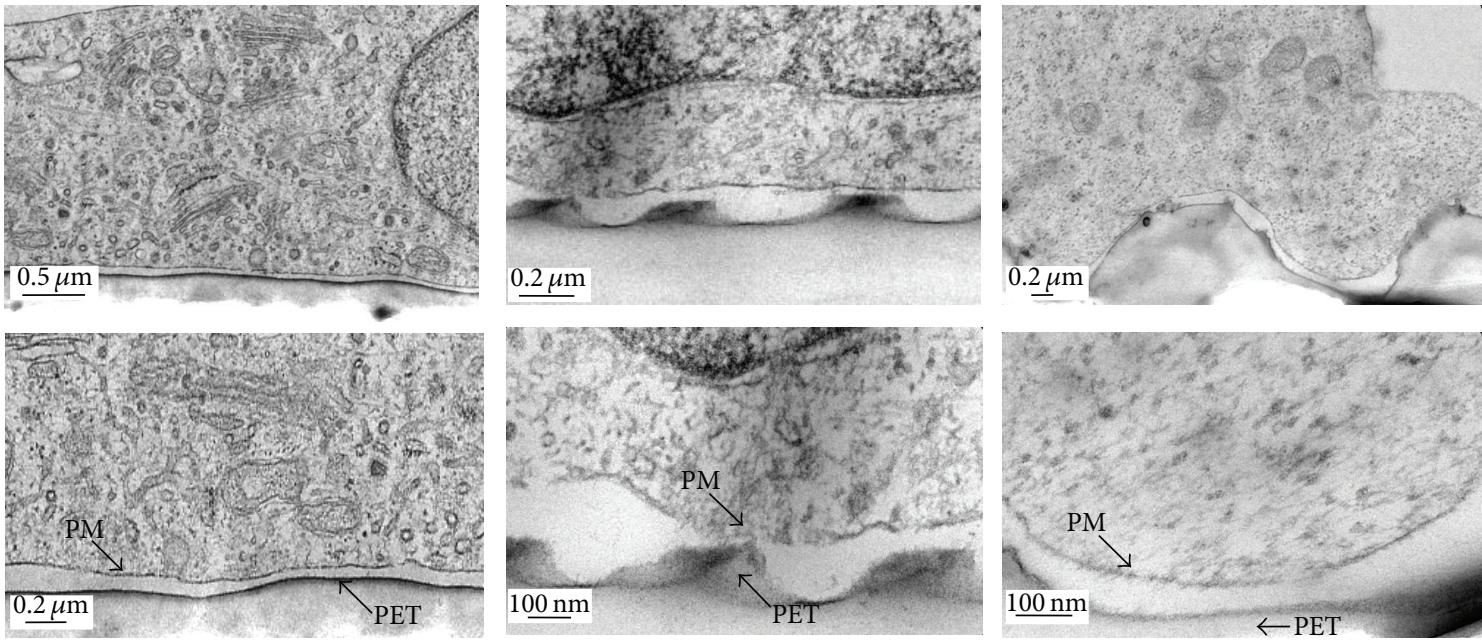

(b)

FIGURE 1: Electron microscopy of laser-irradiated PET substrates. Upper panel: SEM images of resulting structures after excimer laser irradiation of PET substrates. Left: ripples, 6000 pulses of linear polarized $\mathrm{KrF}$ laser radiation $(\lambda=248 \mathrm{~nm})$ at a fluence of $9 \mathrm{~mJ} \mathrm{~cm}{ }^{-2}$. Right: walls, 30 pulses of ArF laser radiation $(\lambda=193 \mathrm{~nm})$ at fluences of $30 \mathrm{~mJ} \mathrm{~cm}{ }^{-2}$. Lower panel: TEM images of HMEC grown on pristine PET (flat, left) or laser irradiated with surface topography (ripples, middle; walls, right); PM and arrow indicate basal plasma membrane; PET and arrow indicate border of PET substrate.

the ripple surface, and cells do not adhere to ripple valleys. In contrast, on wall structures, the basal plasma membrane was found continuously attached to the surface, thereby forming contact on peaks and in valleys of the structure. This observation suggests that divergent attachment architectures of endothelial membranes are generated by contact to these substrates, resulting in the initiation of divergent signaling pathways.

\subsection{Promotion of $\beta$-Catenin Translocation by Ripple Structures} Involves Tyrosine Phosphorylation. Divergent mechanisms of $\beta$-catenin activation by differently sized nanostructures were already suggested by the previously reported observation that both ripples and wall structures are capable of initiating nuclear translocation of $\beta$-catenin, albeit with divergent consequences for $\beta$-catenin target gene expression [5]. To analyse the role of tyrosine kinase activation in detail, we characterized transcriptional activation of cells grown on different surface structures in response to kinase inhibitors. Figures 2 (a)-2(d) show inhibition of $\beta$-catenin nuclear translocation in HMEC cultured on the different substrates in the presence of the tyrosine kinase inhibitors PP2 $(50 \mathrm{nM})$, an inhibitor of the Src family of kinases [24], dasatinib $(3 \mu \mathrm{M})$, which inhibits Src, ILK, and Abl kinases [25-27], and imatinib $(2 \mu \mathrm{M})$, which inhibits Abl kinases only [28].

To quantify translocation levels, the nuclear to cytosolic ratios of $\beta$-catenin immunofluorescence were calculated (Figure 2(e)). Translocation on ripples was significantly reduced by all three inhibitors, indicating that both $\mathrm{Src}$ as well as Abl kinases are essential for that process. The translocation on wall structures, by contrast, was sensitive to Abl kinase inhibition by dasatinib and imatinib, while PP2 was barely effective. These findings further strengthen our hypothesis that differently sized structures activate $\beta$-catenin signaling by divergent mechanisms involving alternative tyrosine kinases.

To test for involvement of focal adhesion kinase (FAK) which is phosphorylated on Tyr397 in response to integrin signaling as a potential initial step of enhanced tyrosine phosphorylation, we immunostained the cells with an antibody against the active form of FAK (Figure 3). Interestingly, we observed high immunoreactivity on flat, pristine PET and on 

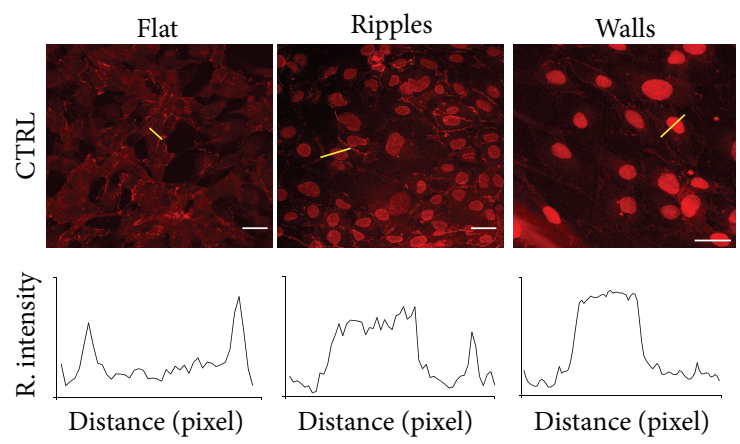

(a)

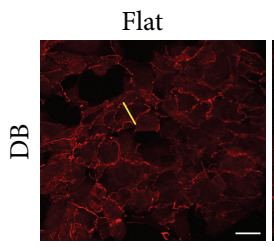

Ripples
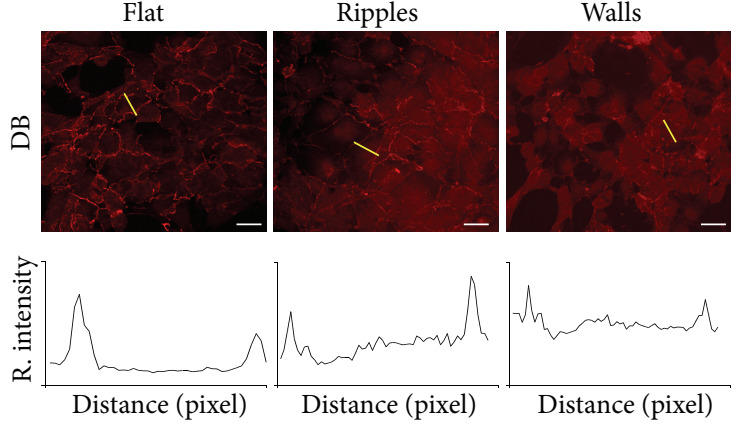

(c)
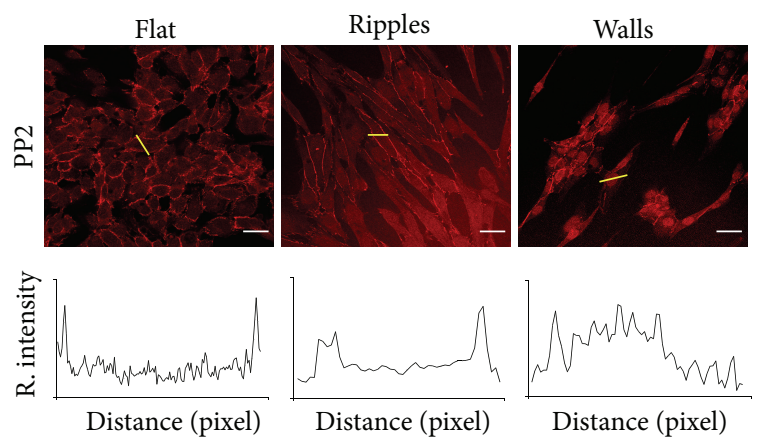

(b)

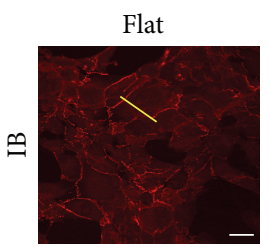

Ripples
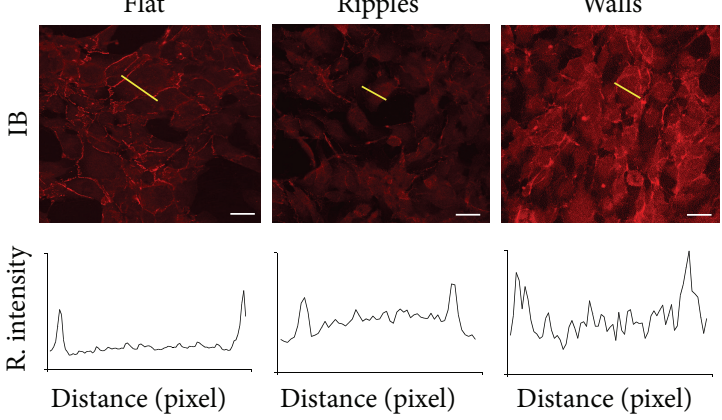

(d)

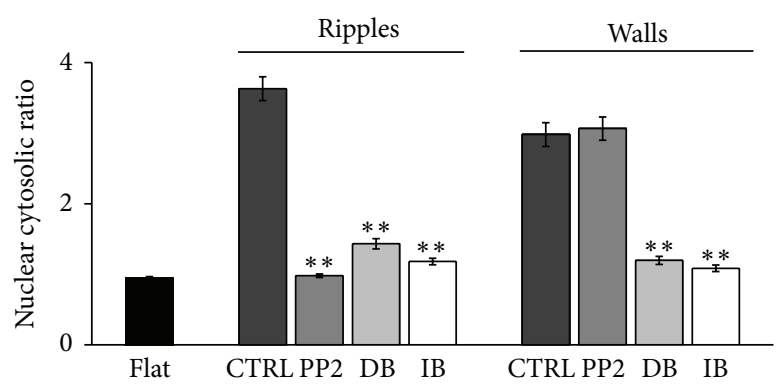

(e)

Figure 2: Nanostructure-induced $\beta$-catenin translocation involves tyrosine phosphorylations. Confocal microscopy images of $\beta$-catenin distribution (red) in HMEC grown on the indicated substrate. Lower panels: representative profile plots along the indicated cell section (yellow line) show intensity distribution of $\beta$-catenin as relative immunofluorescence intensity ( $y$-axis) along the distance in pixel ( $x$-axis). Scale bars represent $10 \mu \mathrm{m}$. CTRL (a); for inhibitor experiments, cells were incubated for $6 \mathrm{~h}$ at $37^{\circ} \mathrm{C}$ with $50 \mathrm{nM} \mathrm{PP} 2$ (b), $3 \mu \mathrm{M}$ dasatinib (DB, (c)), $2 \mu \mathrm{M}$ imatinib (IB, (d)). Bar graphs representing the nuclear to cytosolic ratio of $\beta$-catenin immunofluorescence (e); values \pm SEM; $n \geq 60$ cells from 3 independent experiments, calculated from 3 different images of each experiment; ${ }^{*} P<0.05$; ${ }^{* *} P<0.001$ compared to CTRL.

ripples, but none on walls. This result further supports the concept that different molecular mechanisms of transcriptional control are initiated by ripples and walls structures. Nonetheless, activation of FAK alone is not sufficient to explain the observed enhancement of $\beta$-catenin translocation and proliferation by cell adhesion to ripples.

\subsection{Divergent Impact of Ripples and Wall Structures on} Endothelial $\mathrm{Ca}^{2+}$ Signaling-Evidence for Promotion of Mechanosensitive $\mathrm{Ca}^{2+}$ Entry by Ripples. Another potential mechanism associated with enhanced tyrosine phosphorylation is $\mathrm{Ca}^{2+}$ signaling. $\mathrm{Ca}^{2+}$ entry was reported to control Src activity and Src phosphorylation, which appears as a hallmark of endothelial cells grown on ripples. In turn, Src was found essential for certain mechanisms of $\mathrm{Ca}^{2+}$ entry $[19,21,29]$. This evidence and the observed differences in cell substrate adhesion architecture (Figure 1(b)) led us to hypothesize that mechanosensitive $\mathrm{Ca}^{2+}$ entry may be affected in a specific manner by structured PET substrates. To test our hypothesis, we stimulated cells grown on the different substrates by perfusion-induced shear stress and by depletion of intracellular stores with BHQ as a selective inhibitor of sarcoplasmic/endoplasmic reticulum calcium ATPase (SERCA), [30]. Involvement of mechanosensitive and/or store-operated $\mathrm{Ca}^{2+}$ entry (SOCE) was tested with $\mathrm{Gd}^{3+}$, a common blocker of these cation channels [31, 32]. 

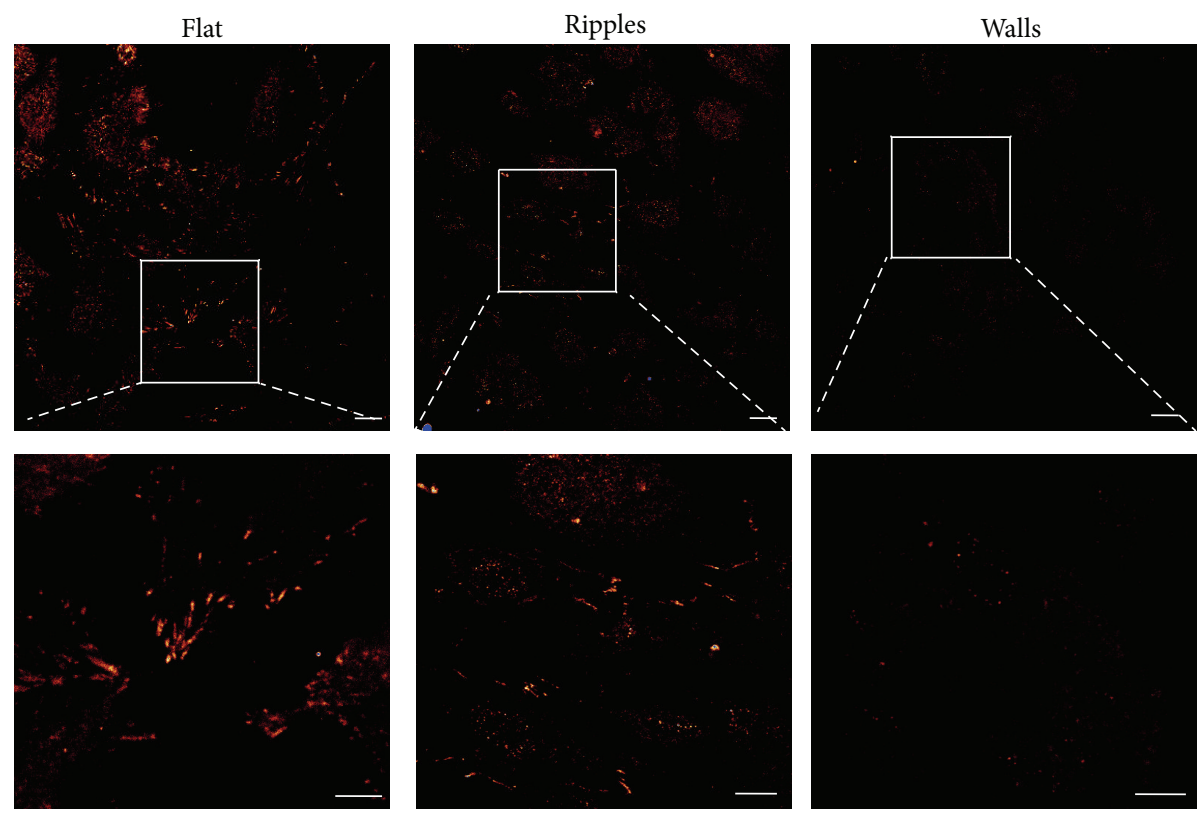

FIGURE 3: Activation of focal adhesion kinase (FAK) is observed on flat and ripples but not on wall structures. Confocal microscopy images show HMEC grown on the indicated substrate, fixed and immunostained with an antibody against the active form of FAK phosphorylated on Tyr397 (red). White square indicates the magnified part (lower panel, microscopic zoom in). Scale bars represent $10 \mu \mathrm{m}$. In Supplementary Figure 2 available online at http://dx.doi.org/10.1155/2013/251063, the images of Figure 3 are shown at enhanced brightness to visualize cell borders and the cell number.

We observed enhanced content of $\mathrm{Ca}^{2+}$ stores by FuraRed AM measurements in cells cultured on ripples as compared to wall structures or flat substrate. Our experiments revealed significant differences in mechanosensitive $\mathrm{Ca}^{2+}$ signaling. Figure 4(a) illustrates basal levels of cytosolic calcium recorded before and after activation of flow-induced shear by perfusion $(2 \mathrm{~min})$. Flow-induced mechanical stress initiated a significant elevation of cytosolic $\mathrm{Ca}^{2+}$ in cells on all three substrates. When cells were preincubated with $\mathrm{Gd}^{3+}(10 \mu \mathrm{M})$, flow-induced $\mathrm{Ca}^{2+}$ elevation on ripples and on flat substrates was abolished, while $\mathrm{Ca}^{2+}$ signals on cells attached to walls remained elevated. Another difference in endothelial $\mathrm{Ca}^{2+}$ signaling was observed when $\mathrm{Ca}^{2+}$ entry was promoted by $\mathrm{BHQ}$-induced store depletion. BHQ elicited a profound cellular $\mathrm{Ca}^{2+}$ response in cells grown on ripples (Figures 4(b) and $4(c)$ ), while cells grown on walls displayed a modest response to BHQ. $\mathrm{Gd}^{3+}$ sensitivity of $\mathrm{Ca}^{2+}$ entry into cells grown on ripples was also clearly evident during stimulation with BHQ. Collectively, these results suggest that mechanosensitive channels, which may be linked to Src kinase activation, govern $\mathrm{Ca}^{2+}$ homeostasis in cells grown on ripples.

\section{4. $\mathrm{Gd}^{3+}$ Inhibits $\beta$-Catenin Translocation and Proliferation} Induced by Ripples but Not by Wall Structures. The observation of $\mathrm{Gd}^{3+}$ sensitive calcium signaling on ripples prompted us to test whether $\mathrm{Gd}^{3+}$ also had an impact on nuclear translocation of $\beta$-catenin. In fact, preincubation with $\mathrm{Gd}^{3+}$ $(10 \mu \mathrm{M})$ for $6 \mathrm{~h}$ significantly reduced nuclear translocation of cells grown on ripples, while there was no effect observed in cells grown on wall structures (Figure 5).
As reported recently [5], culture of HMEC on ripples as well as on wall structures results in enhanced proliferation levels. To investigate the correlation of nuclear $\beta$ catenin translocation and enhanced proliferation, we tested the effects of $\mathrm{Gd}^{3+}$ and tyrosine kinase inhibition by PP2, dasatinib, and imatinib on the expression levels of the proliferation marker Ki67.

By preventing the translocation of $\beta$-catenin, either by inhibiting tyrosine phosphorylation or blocking the mechanosensitive ion channels, proliferation in cells grown on ripples was significantly reduced down to levels in cells grown on flat substrates. Src kinase inhibition again showed no effect on cells grown on wall structures, whereas Abl kinase inhibition led to reduced cell proliferation. Consistent with the observed differences in $\mathrm{Ca}^{2+}$ signaling, $\mathrm{Gd}^{3+}$ failed to inhibit proliferation in cells adherent to walls (Figure 6).

\section{Discussion}

4.1. Periodicity of Substrate Topography Determines Basal Membrane Architecture. Increasing evidence suggests that cell proliferation is strongly affected by specific interactions with the culture substrate. Topographical characteristics appear as important determinants of this interaction and govern cell growth through multiple signaling pathways.

Our results from Figure 1(b) are in line with findings of Teixeira et al. [33], who reported that lamellipodia of cells were able to adhere to valleys of grooves with a width of $2.1 \mu \mathrm{m}$ but not with narrower valleys only $330 \mathrm{~nm}$ wide. They further observed that cells could be elongated and aligned along the structures without focal adhesions and suggested 

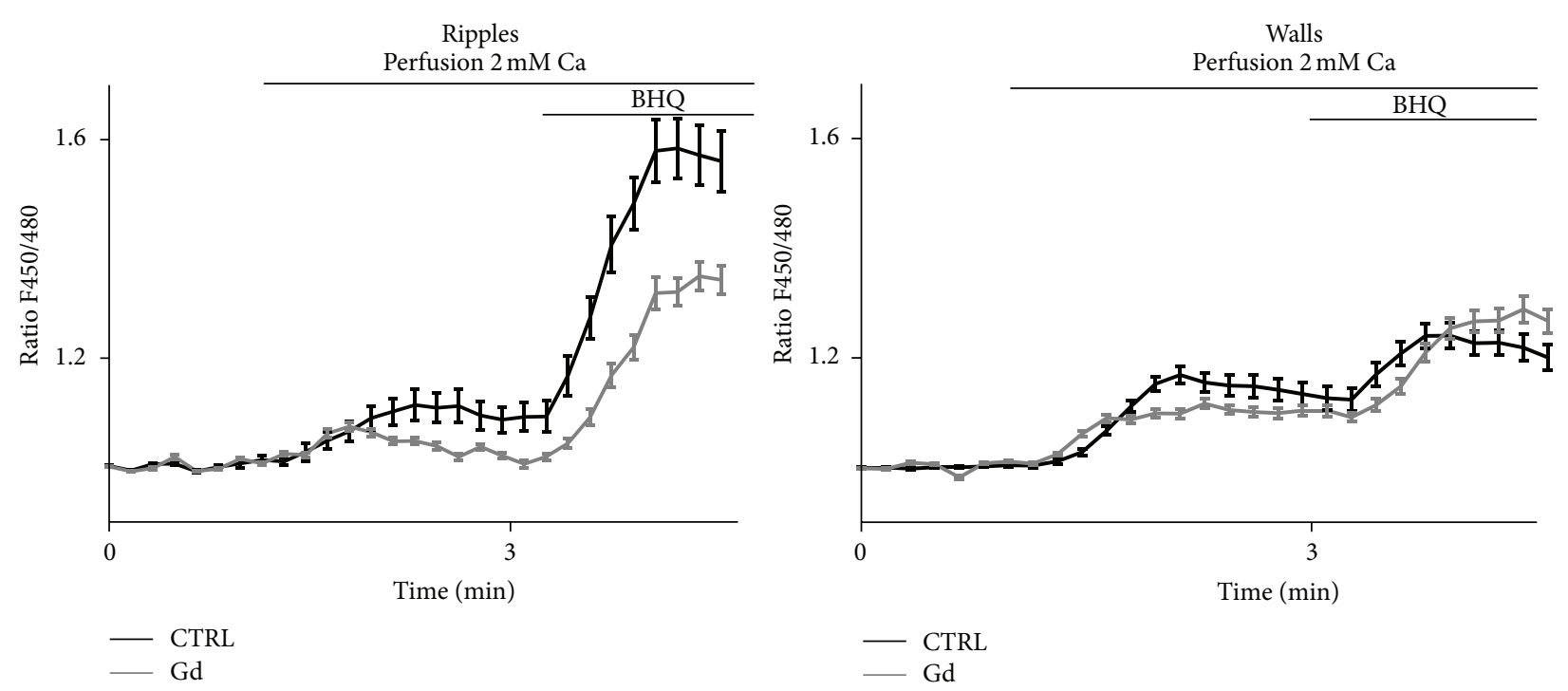

(a)

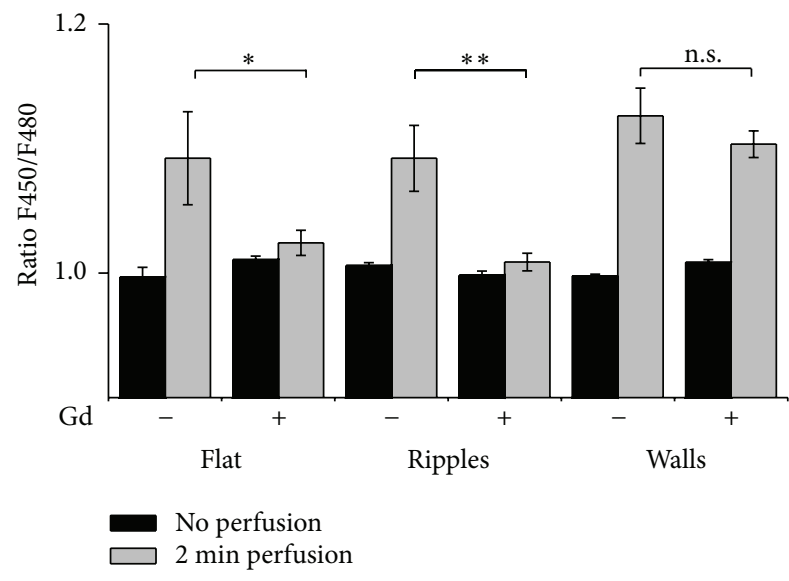

(b)

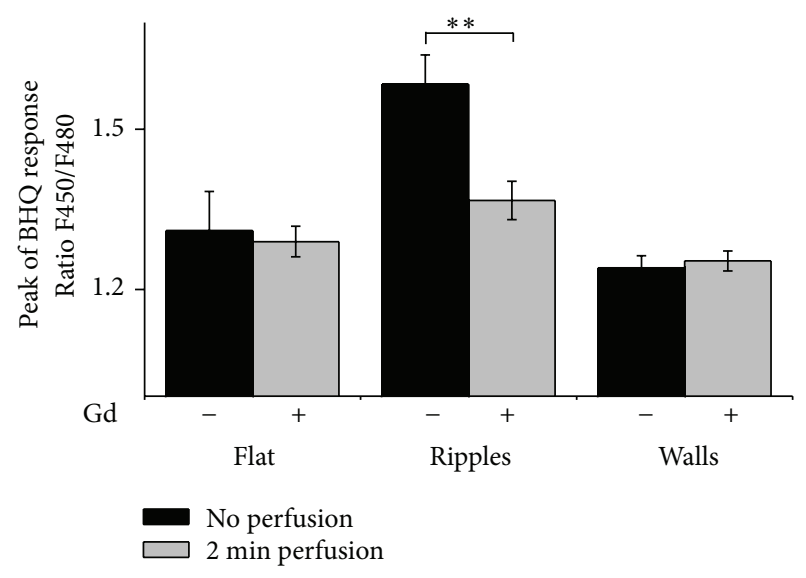

(c)

FIGURE 4: Ripples structures promote a $\mathrm{Gd}^{3+}$-sensitive $\mathrm{Ca}^{2+}$ entry pathway in endothelial cells. Substrates were fixed in a perfusion chamber and after recording the base line for $1 \mathrm{~min}$ perfusion with $2 \mathrm{mM}$ calcium buffer was started. All experiments were carried out with or without $\mathrm{Gd}^{3+}$ preincubation for $6 \mathrm{~h}$. Then, $15 \mu \mathrm{M}$ BHQ was applied. Time course of FuraRed AM measurement of cells grown on the indicated substrate is shown in (a). Data are calculated in $10 \mathrm{sec}$ intervals and averaged. Bar graphs show calcium levels at $30 \mathrm{sec}$ (no perfusion) and after 2 min perfusion (b). The maximum peak after $15 \mu \mathrm{M}$ BHQ stimulation in CTRL and preincubated cells is shown in (c). $n \geq 40$ cells from 3 independent experiments; values for FuraRed AM ratios $\pm \mathrm{SEM} ;{ }^{*} \mathrm{P}<0.05 ;{ }^{* *} \mathrm{P}<0.001$; n.s. $=$ not significant.

that the assembly of these structures was not necessary for contact guidance of epithelial cells. Consistent with these morphological observations, we failed to detect formation of focal adhesions in terms of phosphorylated FAK (Tyr397) when cells were grown on wall structures (Figure 3), which substantially promote alignment of HMEC [5]. Ohara and Buck [34] proposed that focal adhesion contacts are constrained to the peaks of closely spaced nanostructures since limited flexibility of the cell membrane leads to bridging the valleys. Thus focal adhesions were located almost exclusively on top of ridges. This is consistent with our observations that cells growing on ripples had contact to the structure on peaks only (Figure 1(b)).

We conclude that spacing of parallel surface structures is an essential determinant of cell-substrate contact and of formation of focal adhesions. Our results clearly demonstrate size-dependent differences in endothelial cell-substrate interactions and formation of adhesion contacts on nanostructured PET.

\subsection{Role of Tyrosine Kinase Phosphorylations in $\beta$-Catenin} Nuclear Translocation. Recently, $\beta$-catenin was identified as a key player in nanostructure-induced control of cell proliferation [5]. The functions of $\beta$-catenin correspond to certain subcellular localizations of the protein and are governed by a multitude of regulatory phosphorylations [11]. ILK, FAK as well as Src kinases are able to phosphorylate $\beta$ catenin directly and/or influence the cytoplasmic availability of $\beta$-catenin by phosphorylation of GSK3 $\beta$ or, even more indirectly, via impact on the PI3K/Akt pathway $[16-18,35]$. 


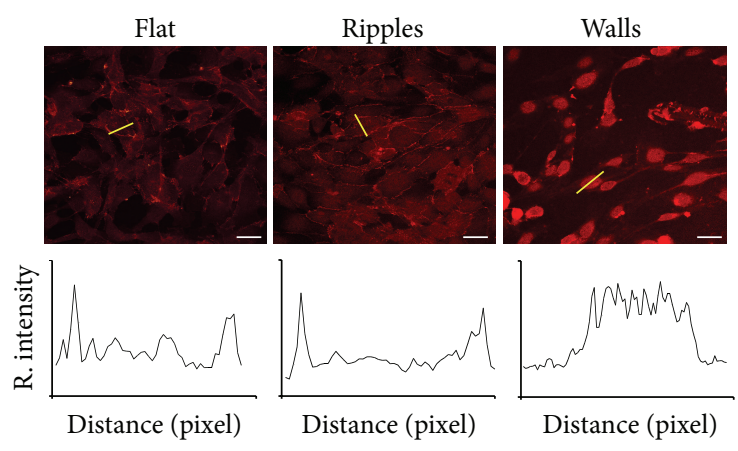

(a)

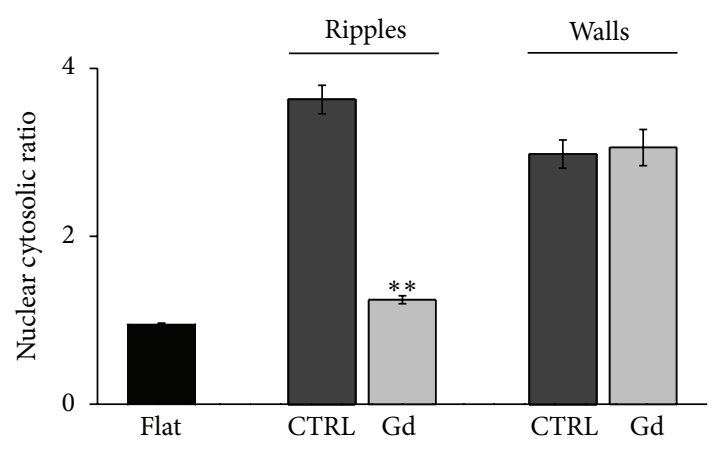

(b)

FIGURE 5: Nuclear translocation of $\beta$-catenin on ripples is sensitive to $\mathrm{Gd}^{3+}$. Confocal microscopy images of $\beta$-catenin distribution (red) in HMEC grown on the indicated substrate. Cells were incubated with $10 \mu \mathrm{M} \mathrm{Gd}^{3+}$ for $6 \mathrm{~h}$ at $37^{\circ} \mathrm{C}$ (a). Lower panels: representative profile plots along the indicated cell section (yellow line) show intensity distribution of $\beta$-catenin as relative immunofluorescence intensity $(y$ axis) along the distance in pixel ( $x$-axis). Scale bars represent $10 \mu \mathrm{m}$. Bar graphs representing the nuclear to cytosolic ratio of $\beta$-catenin immunofluorescence (b); values \pm SEM; $n \geq 60$ from 3 independent experiments, calculated from 3 different images of each experiment; ${ }^{*} P<0.05 ;{ }^{* *} P<0.001$ compared to CTRL.

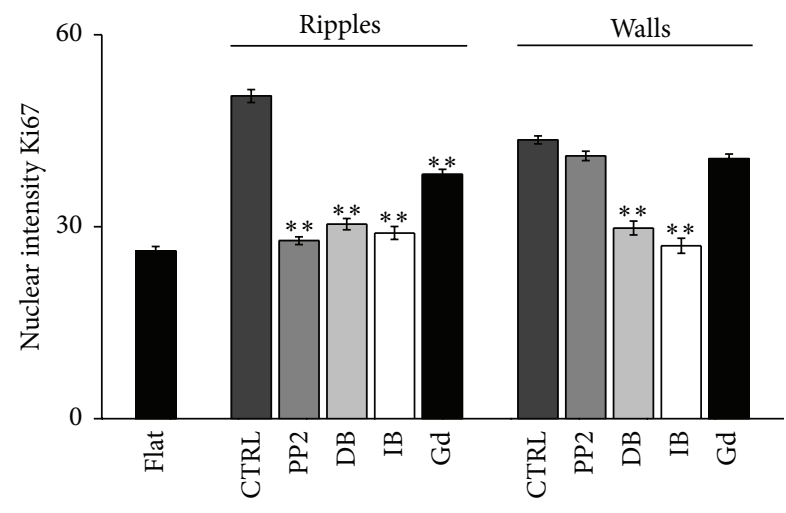

FIGURE 6: Sensitivity of endothelial proliferation on ripples and wall structures to kinase inhibitors, and $\mathrm{Gd}^{3+}$ Bar graphs represent the nuclear immunofluorescence intensity levels of the proliferation marker Ki67. Cells were grown on the indicated substrate and incubated for $6 \mathrm{~h}$ at $37^{\circ} \mathrm{C}$ with $50 \mathrm{nM}$ PP2, $3 \mu \mathrm{M}$ dasatinib (DB), $2 \mu \mathrm{M}$ imatinib (IB), $10 \mu \mathrm{M} \mathrm{Gd}^{3+}$ (Gd), or without inhibitor for control (Values \pm SEM; $n \geq 120$ from 3 independent experiments, calculated from 3 different images of each experiment; ${ }^{*} P<0.05$; ${ }^{* *} P<0.001$ compared to CTRL) (representative confocal images of HMEC immunolabeled with an antibody against Ki67 are shown in Supplementary Figure 3).

Our results provide compelling evidence for the induction of divergent $\beta$-catenin phosphorylation states by differently sized micro/nanostructures. We cannot exclude that $\beta$ catenin distribution is in part disturbed via a reduction of junctional stability. Nonetheless, HMEC cells are able to form mature cell-cell adhesions when grown on nanostructured surfaces (Supplementary Figure 1). Based on our pharmacological analysis, it is suggested that the mechanism which initiates $\beta$-catenin nuclear translocation on ripples involves both Src and Abl kinases, while Src kinases are not involved on wall structures. An interference of these mechanisms with the Wnt/ $\beta$-catenin pathway is likely and requires further investigation.

\subsection{Periodicity of Substrate Topography Determines Calcium} Signaling. Numerous studies reported the involvement of Src kinase signaling in cyclin D1 regulation, cell cycle progression and proliferation [36-38]. Src activity and phosphorylation are strongly dependent on $\mathrm{Ca}^{2+}[19,21,29]$. Moreover, it has been reported that the activity of Src, in turn, is able to promote SOCE fluxes [39-41], which represent an important $\mathrm{Ca}^{2+}$ entry mechanism in endothelial cells relevant for proliferation [42]. Mechanical stress is another factor reported to induce $\mathrm{Ca}^{2+}$ influx downstream of Src [21].

Interestingly, we observed a similar level of shear-induced $\mathrm{Ca}^{2+}$ elevation on all three substrates. Nonetheless, on flat substrates and on ripples, this $\mathrm{Ca}^{2+}$ influx was abolished by $\mathrm{Gd}^{3+}$, a common blocker of mechanosensitive cation channels, while $\mathrm{Gd}^{3+}$ failed to suppress flow-induced $\mathrm{Ca}^{2+}$ rises in cells grown on wall structures. This observation further substantiates the divergent signaling characteristics of cells grown on the different surface topologies. Our results indicate the expression of a particular $\mathrm{Gd}^{3+}$ insensitive subset of mechanosensitive channels in cells grown on wall structures. It is tempting to speculate that such a $\mathrm{Gd}^{3+}$ insensitive subset is formed by $\mathrm{K}^{+}$channels [32], which may confer hyperpolarisation of the plasma membrane and thereby promote $\mathrm{Ca}^{2+}$ influx into endothelial cells [43].

Endothelial cells grown on ripples display a substantially enhanced SOCE. This phenomenon may well be related to the enhanced Src activity [39-41, 44]. It is important to note that $\mathrm{Src}$ and $\mathrm{Ca}^{2+}$ entry are mutually amplifying signaling processes, with Src activity being $\mathrm{Ca}^{2+}$ dependent and SOCE being promoted by Src tyrosine phosphorylation [19, 21, 3941]. At present, we cannot tell which of these processes is initially triggered by the substrate topology. Nonetheless, it appears conceivable to conclude a feed-forward interaction between tyrosine phosphorylation and SOCE being involved in the effects of ripple structures on endothelial gene transcription. Concomitantly enhanced SOCE and Src activity are likely to generate a positive feedback mechanism that promotes $\beta$-catenin tyrosine phosphorylation (Figure 7). 


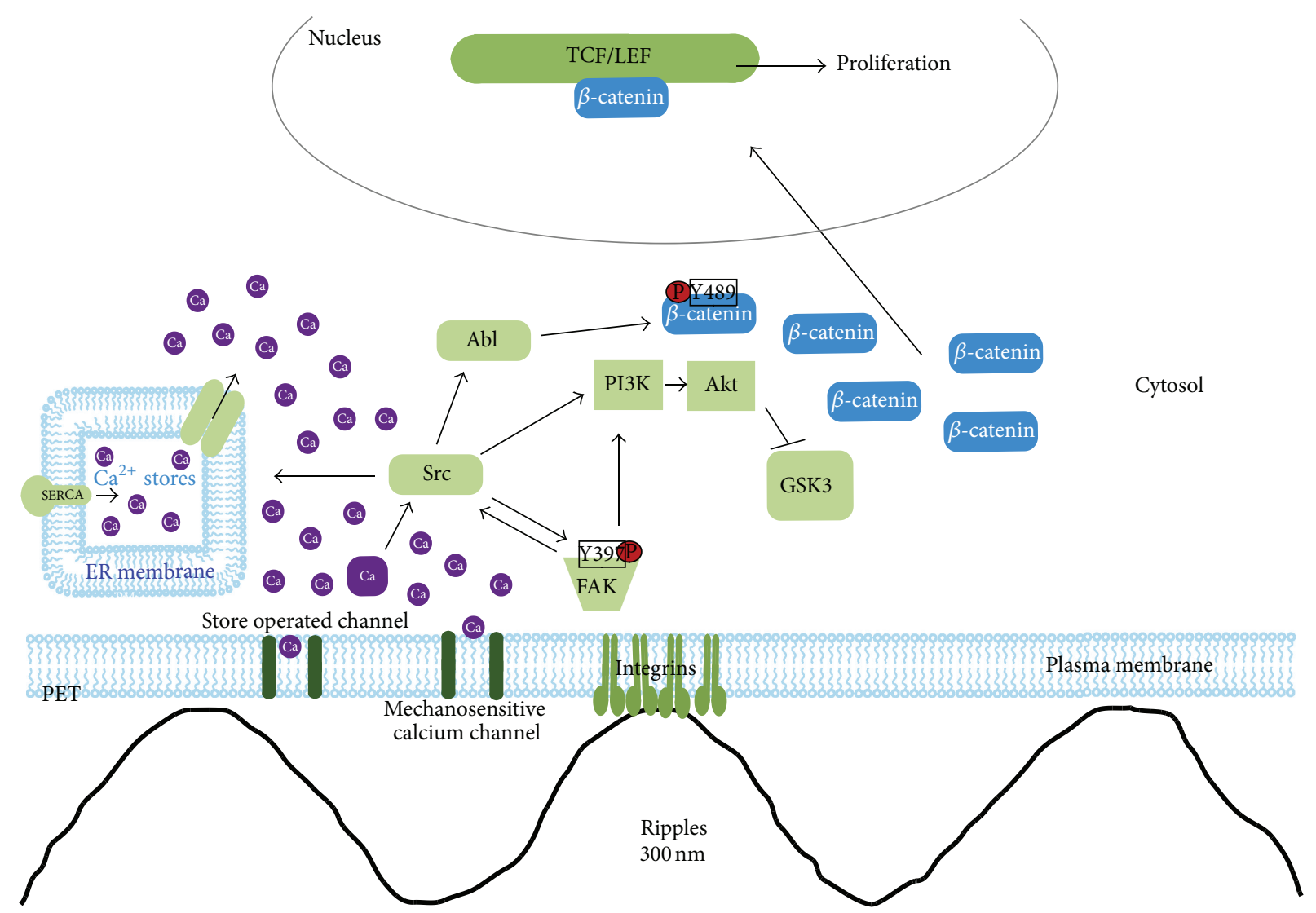

FIGURE 7: Scheme pathway. TCF: T-cell factor; LEF: lymphoid enhancer factor; SERCA: sarcoplasmic/endoplasmic reticulum ATPase; PI3K: phosphatidylinositol 3 kinase; GSK3 $\beta$ : glycogen synthase kinase $3 \beta$; Ca: calcium.

4.4. Tyrosine Phosphorylation and Calcium Signaling Are Essential for Nanostructure-Induced Cell Proliferation. Our experiments identified Src and SOCE activation as key upstream signals involved in $\beta$-catenin activation in endothelial cells grown on ripples, while these processes appear irrelevant for the effects of wall structures. Consistently, inhibition of Src kinases by PP2 or inhibition of $\mathrm{Ca}^{2+}$ entry by $\mathrm{Gd}^{3+}$ had no effect on expression of the proliferation marker Ki67 in cells adherent to wall structures but significantly suppressed $\mathrm{Ki} 67$ expression in cells grown on ripples. Inhibition of $\mathrm{Abl}$ kinases by dasatinib and imatinib on the other hand elicited profound effects on proliferation in cells grown on both types of structures.

In aggregate, our results suggest that enhanced endothelial proliferation initiated by ripples is mediated by joint promotion of tyrosine kinase activity with a leading role of Src and calcium signaling.

\section{Conclusion}

We report significant differences in signalling events initiated by 250 to $300 \mathrm{~nm}$ ripples and $1.5 \mu \mathrm{m}$ wall structures and demonstrate that activation of $\beta$-catenin signaling is strongly dependent on periodicity of PET surface structures. Both micro-(walls-) and nano-(ripple-) structures induce endothelial $\beta$-catenin signaling and proliferation by enhanced tyrosine phosphorylation. Nanostructured ripples control $\beta$-catenin via activation of multiple tyrosine kinases, including Src and promotion of SOCE calcium signaling.

\section{Acknowledgments}

We would like to thank Drs. E. Ades and F. J. Candal of CDC and Dr. T. Lawley of Emroy University for making the HMEC-1 cell line available. We would also like to thank E. Bock and S. Blass for excellent technical assistance. Dasatinib was a kind gift from Dr. Veronika Sexl. The support by the Austrian Science Funds FWF by funding Project F3005 LIPOTOX to Heimo Wolinski and Sepp D. Kohlwein and project P21925-B19 to Klaus Groschner and by the Austrian Research Promotion Agency FFG by Project 838955 CellStretch to Johannes Heitz and Ruxandra-A. Barb is gratefully acknowledged.

\section{References}

[1] E. Martínez, A. Lagunas, C. A. Mills et al., "Stem cell differentiation by functionalized micro- and nanostructured surfaces," Nanomedicine, vol. 4, no. 1, pp. 65-82, 2009.

[2] S. Kruss, T. Wolfram, R. Martin, S. Neubauer, H. Kessler, and J. P. Spatz, "Stimulation of cell adhesion at nanostructured teflon interfaces," Advanced Materials, vol. 22, no. 48, pp. 5499-5506, 2010. 
[3] M. Ventre, F. Causa, and P. A. Netti, "Determinants of cellmaterial crosstalk at the interface: towards engineering of cell instructive materials," Journal of the Royal Society, Interface/the Royal Society, vol. 9, no. 74, pp. 2017-2032, 2012.

[4] S. Pernagallo, O. Tura, M. Wu et al., "Novel biopolymers to enhance endothelialisation of intra-vascular devices," Advanced Healthcare Materials, vol. 1, no. 5, pp. 646-656, 2012.

[5] M. Schernthaner, B. Reisinger, H. Wolinski et al., "Nanopatterned polymer substrates promote endothelial proliferation by initiation of $\beta$-catenin transcriptional signaling," Acta Biomaterialia, vol. 8, no. 8, pp. 2953-2962, 2012.

[6] F. H. Brembeck, M. Rosário, and W. Birchmeier, "Balancing cell adhesion and Wnt signaling, the key role of $\beta$-catenin," Current Opinion in Genetics and Development, vol. 16, no. 1, pp. 51-59, 2006.

[7] T. J. C. Harris and M. Peifer, "Decisions, decisions: $\beta$-catenin chooses between adhesion and transcription," Trends in Cell Biology, vol. 15, no. 5, pp. 234-237, 2005.

[8] F. H. Brembeck, T. Schwarz-Romond, J. Bakkers, S. Wilhelm, M. Hammerschmidt, and W. Birchmeier, "Essential role of BCL9-2 in the switch between $\beta$-catenin's adhesive and transcriptional functions," Genes and Development, vol. 18, no. 18, pp. 22252230, 2004.

[9] C. J. Gottardi and B. M. Gumbiner, "Distinct molecular forms of $\beta$-catenin are targeted to adhesive or transcriptional complexes," The Journal of Cell Biology, vol. 167, no. 2, pp. 339-349, 2004.

[10] T. P. Rao and M. Kühl, "An updated overview on wnt signaling pathways: a prelude for more," Circulation Research, vol. 106, no. 12, pp. 1798-1806, 2010.

[11] T. Valenta, G. Hausmann, and K. Basler, "The many faces and functions of beta-catenin," The EMBO Journal, vol. 31, no. 12, pp. 2714-2736, 2012.

[12] G. E. Hannigan, C. Leung-Hagesteijn, L. Fitz-Gibbon et al., "Regulation of cell adhesion and anchorage-dependent growth by a new $\beta 1$-integrin-linked protein kinase," Nature, vol. 379, no. 6560, pp. 91-96, 1996.

[13] S. K. Hanks, M. B. Calalb, M. C. Harper, and S. K. Patel, "Focal adhesion protein-tyrosine kinase phosphorylated in response to cell attachment to fibronectin," Proceedings of the National Academy of Sciences of the United States of America, vol. 89, no. 18, pp. 8487-8491, 1992.

[14] Y. Wang, G. Jin, H. Miao, J. Y.-S. Li, S. Usami, and S. Chien, "Integrins regulate VE-cadherin and catenins: dependence of this regulation on Src, but not on Ras," Proceedings of the National Academy of Sciences of the United States of America, vol. 103, no. 6, pp. 1774-1779, 2006.

[15] S. Huveneers and E. H. J. Danen, "Adhesion signalingcrosstalk between integrins, Src and Rho," Journal of Cell Science, vol. 122, part 8, pp. 1059-1069, 2009.

[16] J. Lilien and J. Balsamo, "The regulation of cadherin-mediated adhesion by tyrosine phosphorylation/dephosphorylation of $\beta$ catenin," Current Opinion in Cell Biology, vol. 17, no. 5, pp. 459465, 2005.

[17] X. Chen, J. Nam, C. Jean et al., "VEGF-induced vascular permeability is mediated by FAK," Developmental Cell, vol. 22, no. 1, pp. 146-157, 2012.

[18] C. Bertocchi, M. V. Rao, and R. Zaidel-Bar, "Regulation of adherens junction dynamics by phosphorylation switches," Journal of Signal Transduction, vol. 2012, Article ID 125295, 14 pages, 2012.
[19] H. Rangaswami, R. Schwappacher, T. Tran et al., "Protein kinase $\mathrm{G}$ and focal adhesion kinase converge on Src/Akt/betacatenin signaling module in osteoblast mechanotransduction," The Journal of Biological Chemistry, vol. 287, no. 25, pp. 2150921519, 2012.

[20] H. S. Lee, S. J. Millward-Sadler, M. O. Wright, G. Nuki, and D. M. Salter, "Integrin and mechanosensitive ion channeldependent tyrosine phosphorylation of focal adhesion proteins and $\beta$-catenin in human articular chondrocytes after mechanical stimulation," Journal of Bone and Mineral Research, vol. 15, no. 8, pp. 1501-1509, 2000.

[21] S. Katz, R. Boland, and G. Santillán, "Modulation of ERK 1/2 and p38 MAPK signaling pathways by ATP in osteoblasts: Involvement of mechanical stress-activated calcium influx, PKC and Src activation," International Journal of Biochemistry and Cell Biology, vol. 38, no. 12, pp. 2082-2091, 2006.

[22] E. W. Ades, F. J. Candal, R. A. Swerlick et al., "HMEC-1: establishment of an immortalized human microvascular endothelial cell line," Journal of Investigative Dermatology, vol. 99, no. 6, pp. 683-690, 1992.

[23] A. Graziani, M. Poteser, W. Heupel et al., "Cell-cell contact formation governs $\mathrm{Ca}^{2+}$ signaling by TRPC4 in the vascular endothelium: evidence for a regulatory TRPC4- $\beta$-catenin interaction," The Journal of Biological Chemistry, vol. 285, no. 6, pp. 4213-4223, 2010.

[24] J. Bain, L. Plater, M. Elliott et al., "The selectivity of protein kinase inhibitors: a further update," Biochemical Journal, vol. 408, no. 3, pp. 297-315, 2007.

[25] M. Maydan, P. C. McDonald, J. Sanghera et al., "Integrin-linked kinase is a functional $\mathrm{Mn}^{2+}$-dependent protein kinase that regulates glycogen synthase kinase- $3 \beta$ (gsk- $3 \beta$ ) phosphorylation," PLoS ONE, vol. 5, no. 8, Article ID e12356, 2010.

[26] S. Michels, M. Trautmann, E. Sievers et al., "SRC signaling is crucial in the growth of synovial sarcoma cells," Cancer Research, vol. 73, no. 8, pp. 2518-2528, 2013.

[27] N. P. Shah, C. Tran, F. Y. Lee, P. Chen, D. Norris, and C. L. Sawyers, "Overriding imatinib resistance with a novel ABL kinase inhibitor," Science, vol. 305, no. 5682, pp. 399-401, 2004.

[28] M. J. Mauro and B. J. Druker, "STI571: targeting BCR-ABL as therapy for CML," Oncologist, vol. 6, no. 3, pp. 233-238, 2001.

[29] Z. Xie, P. A. Singleton, L. Y. W. Bourguignon, and D. D. Bikle, "Calcium-induced human keratinocyte differentiation requires src- and fyn-mediated phosphatidylinositol 3-kinasedependent activation of phospholipase C- $\gamma 1$," Molecular Biology of the Cell, vol. 16, no. 7, pp. 3236-3246, 2005.

[30] G. A. Moore, D. J. McConkey, G. E. N. Kass, P. J. O’Brien, and S. Orrenius, "2,5-Di(tert-butyl)-1,4-benzohydroquinone-a novel inhibitor of liver microsomal $\mathrm{Ca}^{2+}$ sequestration," FEBS Letters, vol. 224, no. 2, pp. 331-336, 1987.

[31] D. A. Murtazina, D. Chung, A. Ulloa, E. Bryan, H. L. Galan, and B. M. Sanborn, "TRPC1, STIM1, and ORAI influence signalregulated intracellular and endoplasmic reticulum calcium dynamics in human myometrial cells," Biology of Reproduction, vol. 85, no. 2, pp. 315-326, 2011.

[32] O. P. Hamill and D. W. Mcbride Jr., "The pharmacology of mechanogated membrane ion channels," Pharmacological Reviews, vol. 48, no. 2, pp. 231-252, 1996.

[33] A. I. Teixeira, G. A. Abrams, P. J. Bertics, C. J. Murphy, and P. F. Nealey, "Epithelial contact guidance on well-defined microand nanostructured substrates," Journal of Cell Science, vol. 116, part 10, pp. 1881-1892, 2003. 
[34] P. T. Ohara and R. C. Buck, "Contact guidance in vitro. A light, transmission, and scanning electron microscopic study," Experimental Cell Research, vol. 121, no. 2, pp. 235-249, 1979.

[35] A. Oloumi, S. Syam, and S. Dedhar, "Modulation of Wnt3amediated nuclear $\beta$-catenin accumulation and activation by integrin-linked kinase in mammalian cells," Oncogene, vol. 25, no. 59, pp. 7747-7757, 2006.

[36] J. Xing, Z. Zhang, H. Mao, R. G. Schnellmann, and S. Zhuang, "Src regulates cell cycle protein expression and renal epithelial cell proliferation via PI3K/Akt signaling-dependent and -independent mechanisms," American Journal of Physiology-Renal Physiology, vol. 295, no. 1, pp. F145-F152, 2008.

[37] X. Liu, L. Du, and R. Feng, "c-Src regulates cell cycle proteins expression through protein kinase $\mathrm{B} /$ glycogen synthase kinase 3 beta and extracellular signal-regulated kinases $1 / 2$ pathways in MCF-7 cells," Acta Biochimica et Biophysica Sinica, vol. 45, no. 7, pp. 586-592, 2013.

[38] D. Riley, N. O. Carragher, M. C. Frame, and J. A. Wyke, "The mechanism of cell cycle regulation by v-Src," Oncogene, vol. 20, no. 42, pp. 5941-5950, 2001.

[39] G. Babnigg, S. R. Bowersox, and M. L. Villereal, "The role of $\mathrm{pp} 60(\mathrm{c}-\mathrm{src})$ in the regulation of calcium entry via storeoperated calcium channels," The Journal of Biological Chemistry, vol. 272, no. 47, pp. 29434-29437, 1997.

[40] J. A. Rosado, D. Graves, and S. O. Sage, “Tyrosine kinases activate store-mediated $\mathrm{Ca}^{2+}$ entry in human platelets through the reorganization of the actin cytoskeleton," Biochemical Journal, vol. 351, part 2, pp. 429-437, 2000.

[41] J. A. Rosado and S. O. Sage, "Regulation of plasma membrane $\mathrm{Ca}^{2+}$-ATPase by small GTPases and phosphoinositides in human platelets," The Journal of Biological Chemistry, vol. 275, no. 26, pp. 19529-19535, 2000.

[42] I. F. Abdullaev, J. M. Bisaillon, M. Potier, J. C. Gonzalez, R. K. Motiani, and M. Trebak, "Stiml and orail mediate crac currents and store-operated calcium entry important for endothelial cell proliferation," Circulation Research, vol. 103, no. 11, pp. 12891299, 2008.

[43] W. F. Graier, W. R. Kukovetz, and K. Groschner, "Cyclic AMP enhances agonist-induced $\mathrm{Ca}^{2+}$ entry into endothelial cells by activation of potassium channels and membrane hyperpolarization," Biochemical Journal, vol. 291, part 1, pp. 263-267, 1993.

[44] I. Bogeski, M. Bozem, L. Sternfeld, H. W. Hofer, and I. Schulz, "Inhibition of protein tyrosine phosphatase $1 \mathrm{~B}$ by reactive oxygen species leads to maintenance of $\mathrm{Ca}^{2+}$ influx following store depletion in HEK 293 cells," Cell Calcium, vol. 40, no. 1, pp. 1-10, 2006. 

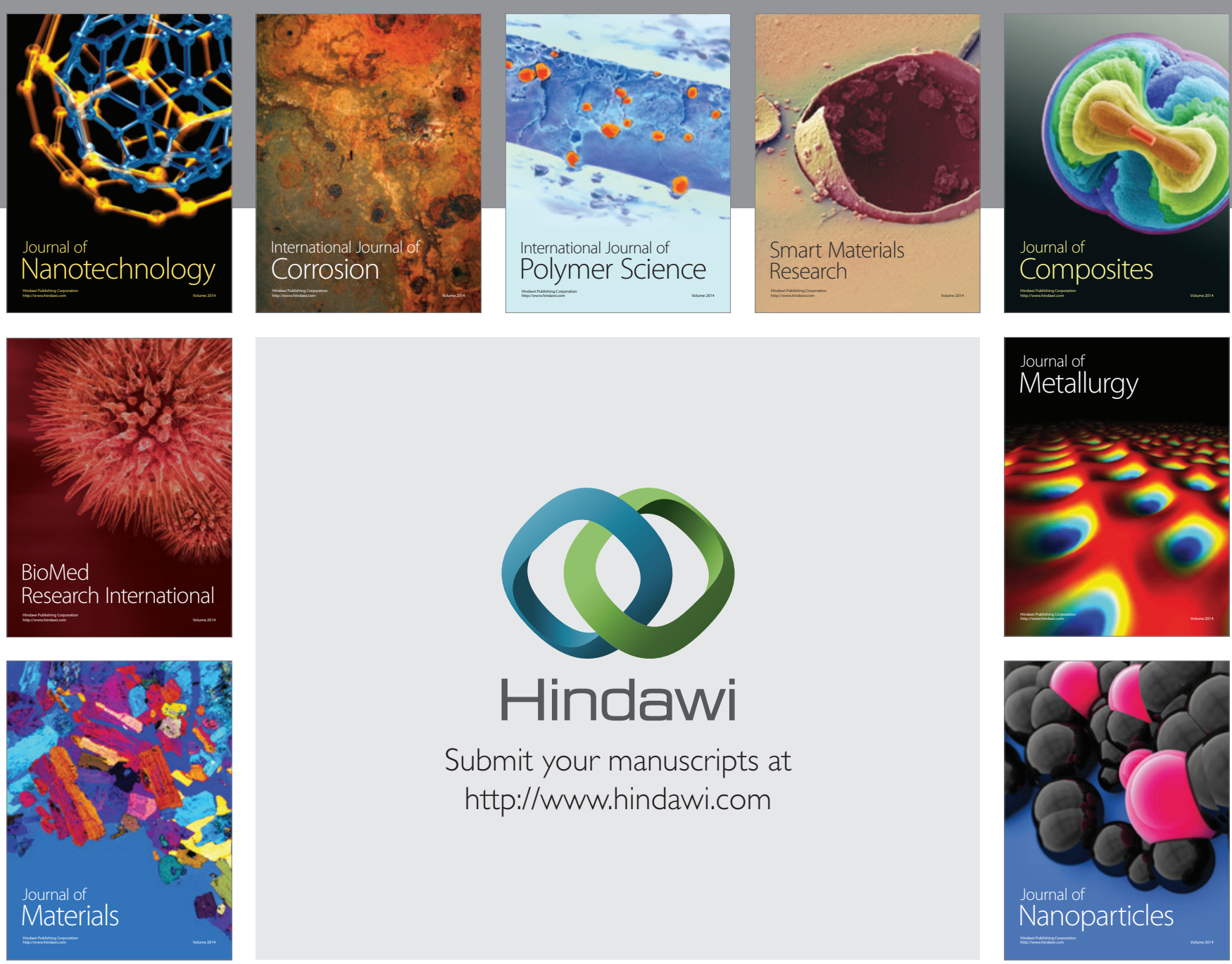

Submit your manuscripts at http://www.hindawi.com
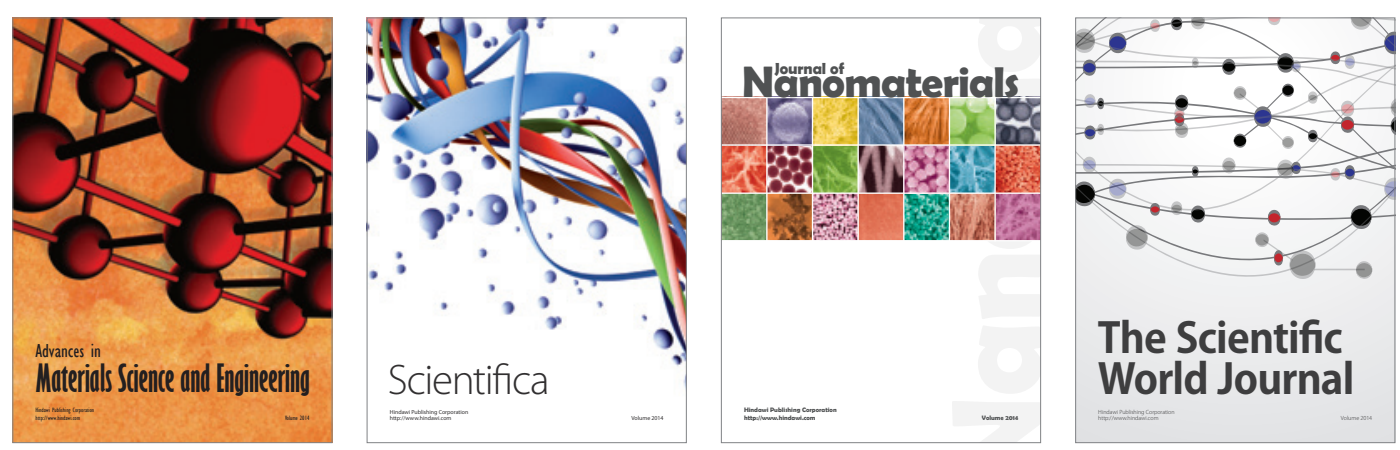

\section{The Scientific World Journal}
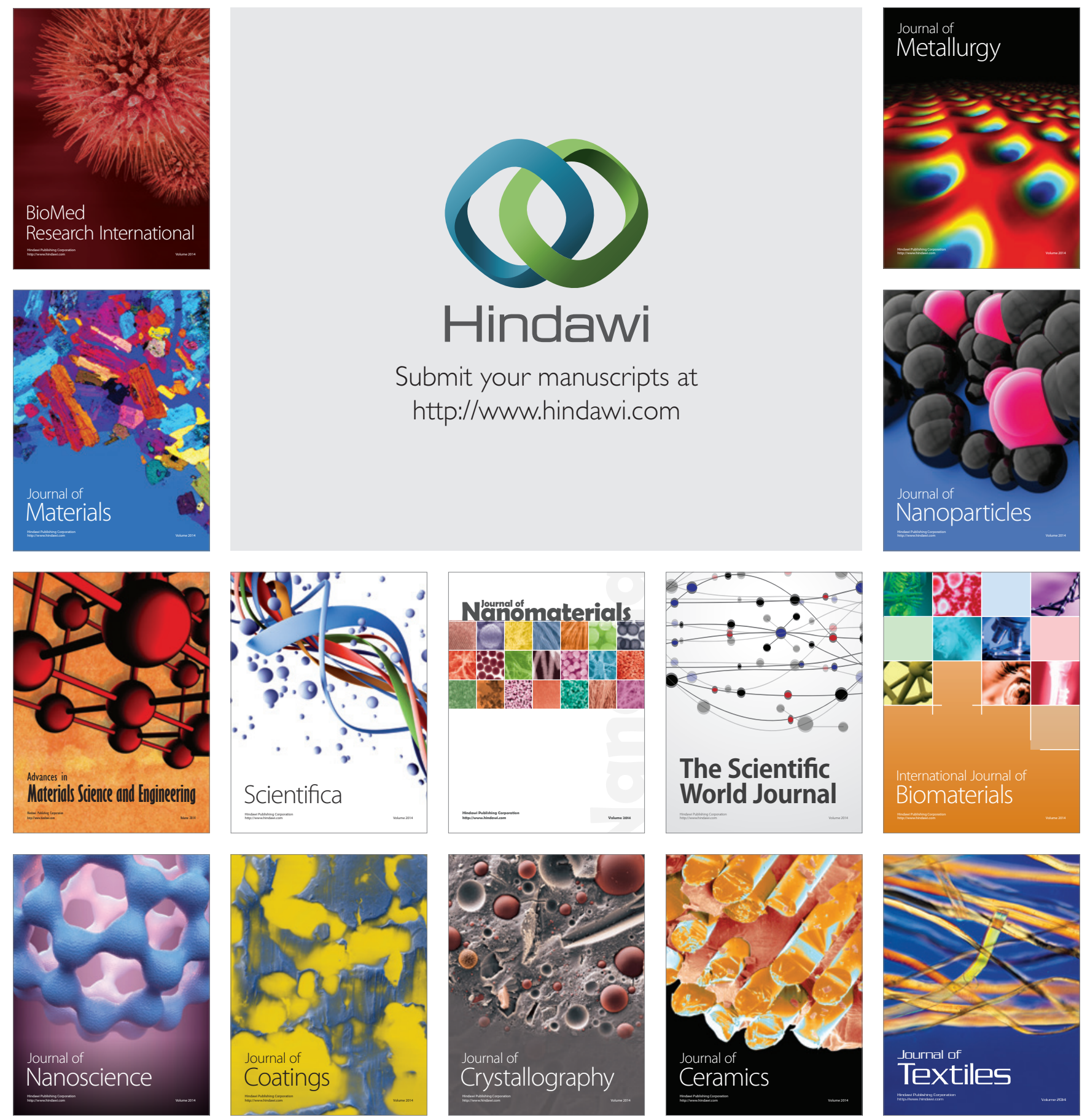